\title{
Evidence for the Existence of High-Energy Photon-Initiated E.A.S.
}

\author{
R. Firkowski, J. Gavin and A. Zawadzki
}

Laboratory of the Nuclear Research Institute of the Polish Academy of Science - Lodz

R. MAZE

Cosmic Physics Laboratory of the French National Centre for Scientific Research Verrières le Buisson (S.-et-O.)

(Il Nuovo Cimento, 29, $19(1963))$

The Fig. 3 page 30 should be replaced by the Fig. 9 page 34 and accordingly the Fig. 9 by the Fig. 3 .

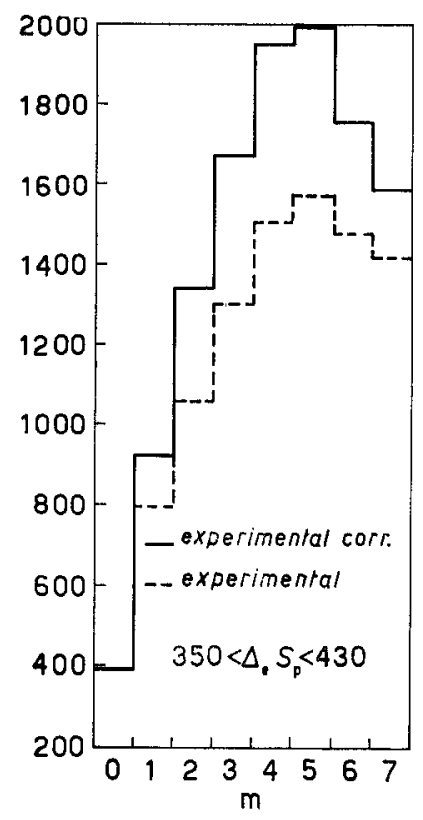

Fig. 3.

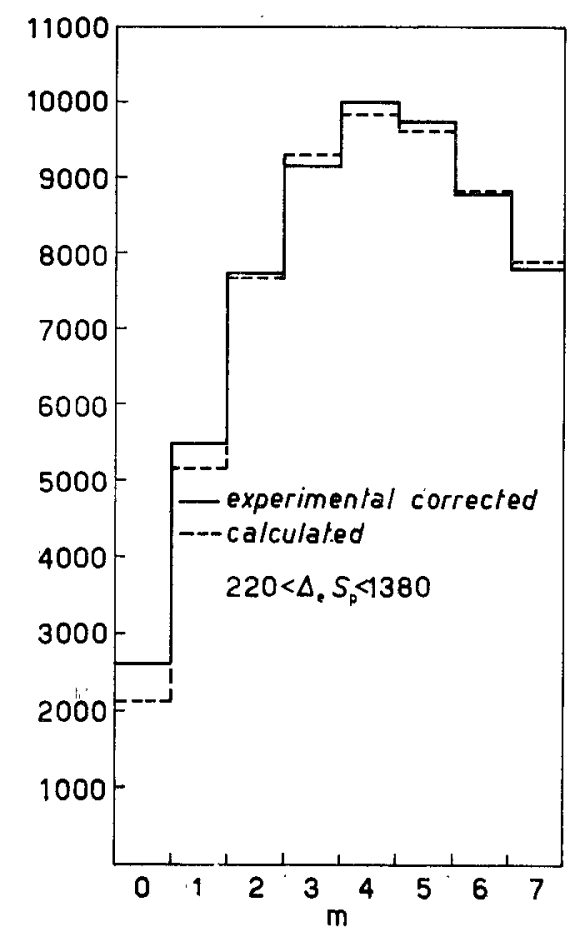

Fig. 9. 